\title{
Severe cutaneous adverse reactions induced by targeted anticancer therapies and immunotherapies
}

This article was published in the following Dove Press journal:

Cancer Management and Research

\author{
Chun-Bing Chen, ${ }^{1-6}$ Ming-Ying \\ Wu, ${ }^{1-4}$ Chau Yee $\mathrm{Ng}^{1-5}$ Chun-Wei \\ Lu, ${ }^{1-6}$ Jennifer Wu, ${ }^{1-4,6}$ Pei-Han \\ Kao, ${ }^{1-4,6}$ Chan-Keng Yang, ${ }^{4-7}$ Meng- \\ Ting Peng, ${ }^{4,6-7}$ Chen-Yang Huang, ${ }^{4,6-7}$ \\ Wen-Cheng Chang, ${ }^{4,6-7}$ Rosaline \\ Chung-Yee Hui, ${ }^{1-4}$ Chih-Hsun \\ Yang, ${ }^{1-4}$ Shun-Fa Yang, ${ }^{8,9}$ Wen-Hung \\ Chung, ${ }^{1-4,6,10,11}$ Shih-Chi Su ${ }^{1-4,10}$ \\ 'Department of Dermatology, Drug \\ Hypersensitivity Clinical and Research \\ Center, Chang Gung Memorial Hospital, \\ Linkou, Taiwan; ${ }^{2}$ Department of Dermatology, \\ Drug Hypersensitivity Clinical and Research \\ Center, Chang Gung Memorial Hospital, \\ Taipei, Taiwan; ${ }^{3}$ Department of Dermatology, \\ Drug Hypersensitivity Clinical and Research \\ Center, Chang Gung Memorial Hospital, \\ Keelung, Taiwan; ${ }^{4}$ College of Medicine, Chang \\ Gung University, Taoyuan, Taiwan; ${ }^{5}$ Graduate \\ Institute of Clinical Medical Sciences, College \\ of Medicine, Chang Gung University, Taoyuan, \\ Taiwan; 6 Immune-Oncology Center of \\ Excellence, Chang Gung Memorial Hospital, \\ Linkou, Taiwan; 'Division of Hematology- \\ Oncology, Department of Internal Medicine, \\ Chang Gung Memorial Hospital, Linkou, Taiwan; \\ ${ }^{8}$ Institute of Medicine, Chung Shan Medical \\ University, Taichung, Taiwan; ${ }^{9}$ Department \\ of Medical Research, Chung Shan Medical \\ University Hospital, Taichung, Taiwan; ${ }^{10}$ Whole- \\ Genome Research Core Laboratory of Human \\ Diseases, Chang Gung Memorial Hospital, \\ Keelung, Taiwan; "Department of Dermatology, \\ Xiamen Chang Gung Hospital, Xiamen, China
}

Correspondence: Shun-Fa Yang Institute of Medicine, Chung Shan Medical University, I 10 Chien-Kuo North Road Section I, Taichung 402, Taiwan

Tel +886424739595 ext 34253

Fax +886 424723229

Email ysf@csmu.edu.tw

Shih-Chi Su

Whole-Genome Research Core Laboratory of Human Diseases, Chang Gung Memorial Hospital, Number 222, Maijin Road, Anle Distrist, Keelung City 204, Taiwan

Tel +88622713 521I ext 3397

Fax +886227191623

Email ssul@cgmh.org.tw
Abstract: With the increasing use of targeted anticancer drugs and immunotherapies, there have been a substantial number of reports concerning life-threatening severe cutaneous adverse reactions (SCARs), including Stevens-Johnson syndrome (SJS), toxic epidermal necrolysis (TEN), drug rash with eosinophilia and systemic symptoms, drug-induced hypersensitivity syndrome, and acute generalized exanthematous pustulosis. Although the potential risks and characteristics for targeted anticancer agent- and immunotherapy-induced SCAR were not well understood, these serious adverse reactions usually result in morbidity and sequela. As a treatment guideline for this devastating condition is still unavailable, prompt withdrawal of causative drugs is believed to be a priority of patient management. In this review, we outline distinct types of SCARs caused by targeted anticancer therapies and immunotherapies. Also, we discuss the clinical course, latency, concomitant medication, tolerability of rechallenge or alternatives, tumor response, and mortality associated with these devastating conditions. Imatinib, vemurafenib, and rituximab were the top three offending medications that most commonly caused SJS/TEN, while EGFR inhibitors were the group of drugs that most frequently induced SJS/TEN. For drug rash with eosinophilia and systemic symptoms/drug-induced hypersensitivity syndrome and acute generalized exanthematous pustulosis, imatinib was also the most common offending drug. Additionally, we delineated 10 SCAR cases related to innovative immunotherapies, including PD1 and CTLA4 inhibitors. There was a wide range of latency periods: 5.5-91 days (median). Only eight of 16 reported patients with SCAR showed clinical responses. Targeted anticancer drugs and immunotherapies can lead to lethal SCAR (14 deceased patients were identified as suffering from SJS/TEN). The mortality rate of TEN was high: up to $52.4 \%$. The information compiled herein will serve as a solid foundation to formulate ideas for early recognition of SCAR and to discontinue offending drugs for better management.

Keywords: acute generalized exanthematous pustulosis, drug rash, eosinophilia, Stevens-Johnson syndrome, toxic epidermal necrolysis, targeted therapy, immunotherapy

\section{Introduction}

There has been rapidly increasing use of targeted anticancer therapies and immunotherapies in the clinical oncology field. Although targeted agents used for cancer treatment are generally better tolerated than conventional chemotherapy, cutaneous adverse events following the administration of targeted agents are not sparse. Manifestations of cutaneous adverse reactions induced by targeted agents vary greatly due to distinct molecular and pathological mechanisms, such as rashes, alopecia, hand-foot skin reactions, nail changes, and hair changes. ${ }^{1}$ However, it has been reported that an increasing number of targeted agents induce life-threatening severe cutaneous adverse reactions 
(SCARs), including Stevens-Johnson syndrome (SJS)/toxic epidermal necrolysis (TEN), drug rash with eosinophilia and systemic symptoms (DRESS)/drug-induced hypersensitivity syndrome (DIHS), and acute generalized exanthematous pustulosis (AGEP). ${ }^{2}$ Unlike mild forms of cutaneous toxicity, these SCARs are idiosyncratic and potentially fatal. ${ }^{3}$ However, the risk of SCARs caused by targeted anticancer therapies and immunotherapies remains poorly characterized. SJS/TEN typically present as a rapidly developing blistering exanthema of purpuric macules and target-like lesions accompanied by mucosal and skin detachment, in which SJS involves $<10 \%$ of body surface area skin detachment and TEN $>30 \% .{ }^{4}$ Although rare, they are potentially fatal, with a mortality rate of $10 \%$ for SJS, 30\% for SJS-TEN overlapping, and 50\% for TEN (Figure 1). ${ }^{4-6} \mathrm{SJS} / \mathrm{TEN}$ also commonly causes long-term sequelae of the skin and eyes. ${ }^{7}$ In addition, DRESS or DIHS usually mani-

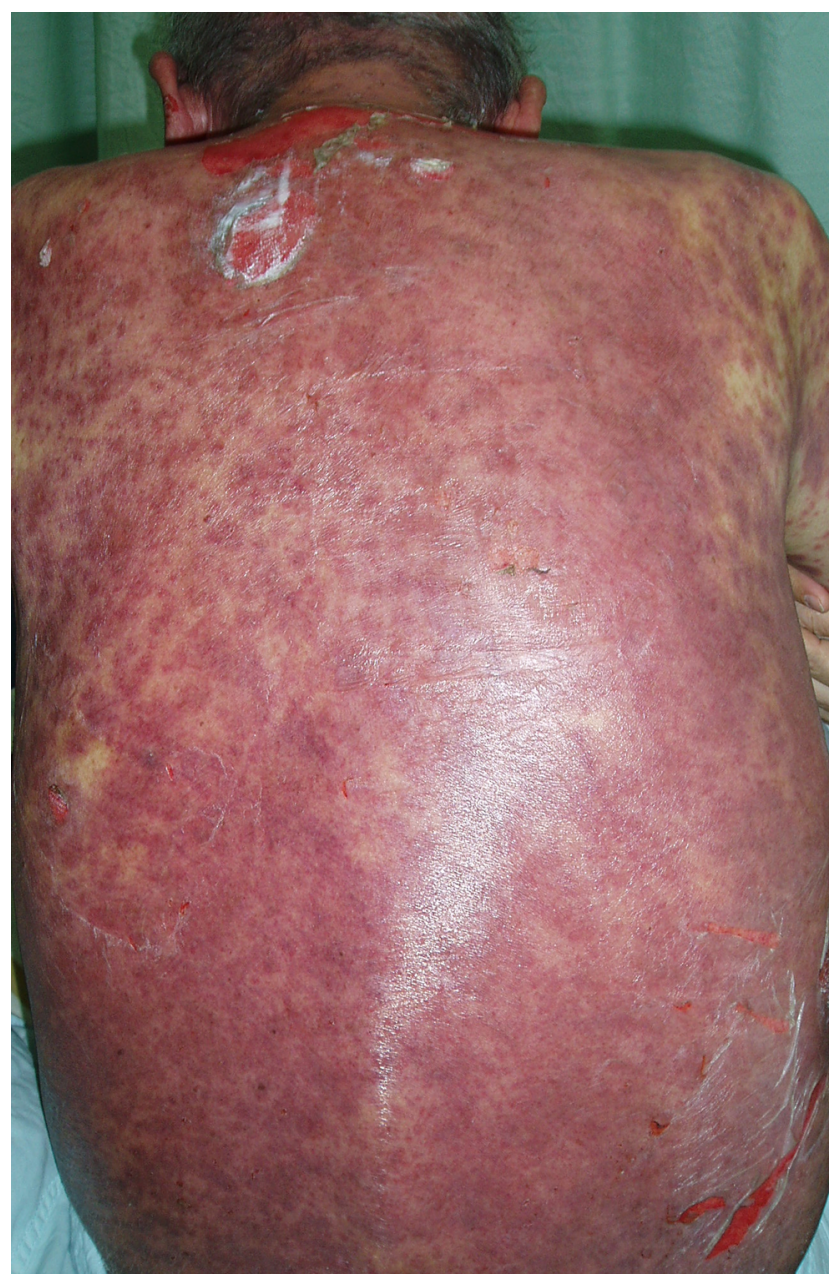

Figure I Fatal toxic epidermal necrolysis after cetuximab treatment for 8 weeks. Notes: A 74-year-old man who had moderately differentiated metastatic colon adenocarcinoma presented diffuse erythematous plaques with dusky red centers on trunk and extremities after treatment with cetuximab for 8 weeks. The skin rashes were confluent and formed large blisters or skin detachments involving more than $70 \%$ of the body surface area. fest with a complex natural course, including fever, cutaneous involvement with typical skin eruptions (eg, generalized maculopapular exanthema, facial edema, infiltration, and purpuric change other than lower extremities), laboratory abnormalities (atypical lymphocytosis and eosinophilia), lymphadenopathy, and systemic organ involvement (eg, liver, kidneys, and lungs; Figure 2). ${ }^{8,9}$ The mortality rate for DRESS is approximately up to $10 \% .{ }^{10} \mathrm{AGEP}$, another phenotype of SCAR, is characterized by a sudden eruption of mainly small nonfollicular pustules on a background of erythema with systemic involvement associated with fever and neutrophilia. ${ }^{11}$ The course is relatively benign, but $4 \%$ of AGEP cases still develop to life-threatening situations. ${ }^{11}$ Due to the high morbidity and mortality, early diagnosis of SCAR and prompt medication discontinuation are required for better management. This review article summarizes SCARs induced by distinct targeted anticancer agents and immunotherapies and also delineates the clinical course, duration of anticancer drugs, concomitant medication, tolerability of rechallenge or alternative agents, tumor response with regard to the occurrence of SCAR, and mortality rate associated with these devastating conditions.

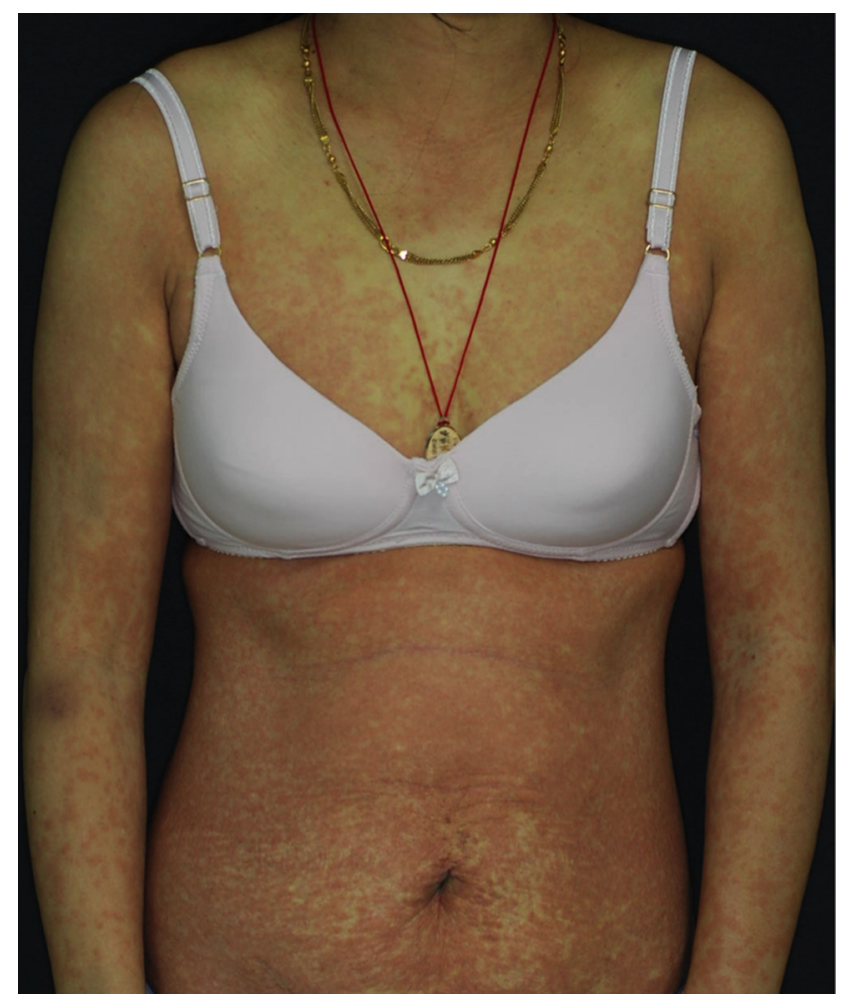

Figure 2 Drug rash with eosinophilia and systemic symptoms after erlotinib treatment for 4 weeks.

Notes: A 60-year-old woman with EGFR-mutant metastatic lung adenocarcinoma treated with erlotinib for 4 weeks. She developed generalized infiltrative exanthema on trunk and limbs accompanied by fever, acute liver failure, coagulopathy, and leukocytosis with eosinophilia. Further lymphocyte activation testing confirmed a hypersensitivity reaction to erlotinib. 


\section{Search strategy and selection criteria}

A literature search was performed for papers from 1950 to September 2017 on Embase, Web of Science, Scopus, and Ovid using the terms Stevens-Johnson syndrome (SJS), toxic epidermal necrolysis (TEN), drug rash with eosinophilia and systemic symptoms (DRESS), drug-induced hypersensitivity syndrome (DIHS), or acute generalized exanthematous pustulosis (AGEP) combined with targeted therapy drugs and immunotherapies. Primary case reports, case series, reports from clinical trials, and postmarketing surveillance were included. All published peer-reviewed literature from the search was reviewed (reports were limited to the English language only, with inclusion of selected non-English reports with abstracts in English). Histopathologic confirmation for the diagnosis of SCAR was not required for the inclusion criteria. Clinical course, duration of anticancer drugs, concomitant medication, tolerability of rechallenge or alternative agents, tumor response with regard to the occurrence of SCARs, and mortality were analyzed.

\section{Clinical course}

\section{Characteristics and demographic data}

A search of peer-reviewed literature yielded 73 reports of SCARs: SJS/TEN ( $\mathrm{n}=54)$, DRESS $(\mathrm{n}=8)$, AGEP $(\mathrm{n}=10)$, and DRESS-AGEP overlapping ( $\mathrm{n}=1$; Table 1$)$. These reported SCAR cases were associated with 17 targeted anticancer agents and immunotherapies, including EGFR inhibitors (afatinib, cetuximab, erlotinib, gefitinib, panitumumab, and vandetanib), multikinase inhibitors (imatinib), antiangiogenic agents (sorafenib), proteasome (bortezomib), anti-CD20 (rituximab), anti-CD30 (brentuximab vedotin), BRAF inhibitors (vemurafenib), recombinant IL2 (aldesleukin), recombinant IL2 and diphtheria toxin (denileukin), anti-PD1 (nivolumab and pembrolizumab), and anti-CTLA4 (ipilimumab). Among 54 cases of SJS-TEN, there were 29 SJS, four SJS-TEN overlapping, and 20 TEN cases. Imatinib $(n=12)$, vemurafenib $(n=7)$, and rituximab $(n=5)$ were identified as the top three offending medications to cause SJS/TEN. EGFR inhibitors ( $n=12)$ were the most common group of drugs to induce SJS/TEN, including cetuximab $(n=4)$, afatinib $(n=2)$, gefitinib $(n=2)$, vandetanib $(n=2)$, erlotinib $(n=1)$, and panitumumab $(n=1)$. Imatinib was also the most common offending drug to induce DERSS and AGEP. One infrequent overlapping DRESS-AGEP case was reported in one vemurafenib user. ${ }^{12}$ For newly developed immunomodulatory therapeutic antibodies targeting inhibitory receptors expressed by $\mathrm{T}$ cell, such as CTLA4 and PD1, there was one ipilimumab SJS, one ipilimumab TEN, one ipilimumab DRESS, one ipilimumab AGEP, two nivolumab TEN, and four pembrolizumab SJS. In total, latent periods of the anticancer agents were variable in different drug classes, from 5.5 days (aldesleukin) to 91 days (denileukin) (median).

The diagnosis of these SJS/TEN was mainly based on clinical manifestation, with 30 cases (55.6\%) confirmed by histopathology. Direct immunofluorescence (DIF) or indirect IF (IIF) to rule out the possibility of other autoimmune diseases was performed in seven cases. For mucosal involvement of SJS/TEN, oral mucosa (35 of 54, 64.8\%) was more common than ocular (20 of 54, 37\%) or genital mucosa (17 of 54, $31.5 \%$ ) involvement. Positive Nikolsky signs were mentioned in 17 cases. Laboratory examinations to exclude etiologies other than drug-induced SJS/TEN, such as serology data of mycoplasma, herpes simplex infection, or viral culture were done in six cases, and all showed negative results.

\section{Tolerability}

Eighteen patients underwent rechallenge of the same anticancer drugs: one aldesleukin TEN, one denileukin TEN, one erlotinib SJS, one gefitinib AGEP, seven imatinib SJS, two imatinib DRESS, one imatinib AGEP, one ipilimumab AGEP, one sorafenib SJS, one sorafenib AGEP, and one vemurafenib SJS. Among patients with rechallenge, four imatinib SJS/TEN cases tolerated well with slow titration, with systemic corticosteroid used concomitantly in three cases (Table 2). In addition, one vemurafenib SJS showed recurrence with rash and fever after one 50\% dose rechallenge, but then tolerated with a program of desensitization with dexamethasone. ${ }^{13}$ However, the other 13 patients had recurrence with different manifestations after rechallenge. Among the eight patients who had received alternative agents with the same class of anticancer drugs, five of eight tolerated well: one gefitinib TEN tolerating icotinib, two imatinib SJS patients tolerating dasatinib, one imatinib DRESS patient tolerated a nilotinib replacement, and one vemurafenib TEN patient was switched successfully to dabrafenib with gradual escalation. However, one afatinib SJS patient suffered liver damage after erlotinib and gefitinib were administered, one cetuximab SJS patient progressed into SJS/TEN after panitumumab treatment, and one imatinib SJS patient had possible cross-reactivity with dasatinib concomitant with sulfamethoxazole-trimethoprim at the same time. One vemurafenib TEN patient who underwent a lymphocyte transformation test (LTT) assay confirmed the 


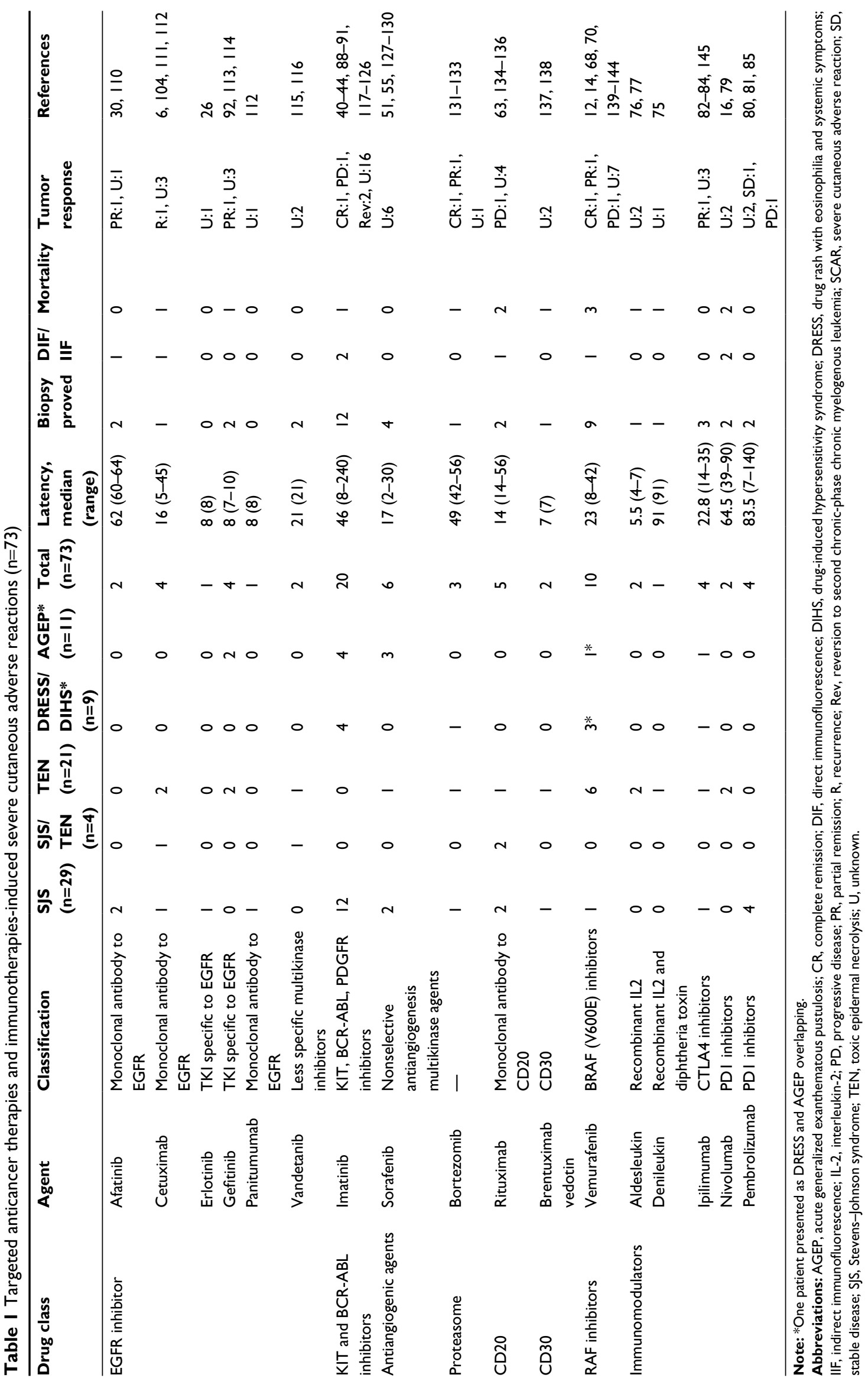


Table 2 Tolerability follow-up for rechallenge or alternatives in patients with targeted anticancer therapies and immunotherapyinduced severe cutaneous adverse reactions $(n=25)$

\begin{tabular}{|c|c|c|c|c|}
\hline Agent & Phenotype & Rechallenge & Tolerability to other drugs & Reference \\
\hline Afatinib & SJS & Not reported & $\begin{array}{l}\text { Erlotinib (liver damage); gefitinib } \\
\text { (liver damage) }\end{array}$ & 30 \\
\hline Aldesleukin & TEN & $\begin{array}{l}\text { Recurrent with diffuse erythema and punctuated lesions over } \\
\text { left forearm }\end{array}$ & & 76 \\
\hline Cetuximab & SJS & Not reported & Panitumumab (SJS/TEN) & 112 \\
\hline Denileukin & TEN & $\begin{array}{l}\text { Recurrent with extensive erythema and edema with flaccid } \\
\text { bulla, and denudation was apparent on flanks, thighs, and arms }\end{array}$ & & 75 \\
\hline Erlotinib & SJS & $\begin{array}{l}\text { Recurrent with continued erythematous and congested } \\
\text { eruption on the face }\end{array}$ & & 26 \\
\hline Gefitinib & TEN & Not reported & Icotinib (tolerance) & 114 \\
\hline Gefitinib & AGEP & $\begin{array}{l}\text { Recurrent with few pustules on previous skin lesion, but } \\
\text { tolerated with continuation }\end{array}$ & & 92 \\
\hline Imatinib & SJS & Not reported & $\begin{array}{l}\text { Dasatinib (possible cross-reactivity } \\
\text { but taking sulfamethoxazole- } \\
\text { trimethoprim at the same time); } \\
\text { nilotinib (tolerance) }\end{array}$ & 1,117 \\
\hline Imatinib & SJS & Recurrent with lesions flared up at lower doses & Dasatinib (tolerance) & 118 \\
\hline Imatinib & SJS & $\begin{array}{l}\text { Recurrent with perioral pruritic eruption after reinitiation } \\
\text { at a lower dose of } 200 \mathrm{mg} / \text { day, but then tolerated with } \\
\text { slow titration }(100-300 \mathrm{mg} / \text { day }) \text { with } 100 \mathrm{mg} \text { together with } \\
\text { prednisolone }(1 \mathrm{mg} / \mathrm{kg})\end{array}$ & Not reported & 40 \\
\hline Imatinib & SJS & $\begin{array}{l}\text { Tolerance with slow titration from } 100 \mathrm{mg} / \text { day gradually } \\
\text { escalated to } 400 \mathrm{mg} / \text { day }\end{array}$ & Not reported & 41 \\
\hline Imatinib & SJS & $\begin{array}{l}\text { Tolerance with slow titration from } 100 \mathrm{mg} / \text { day and } \\
\text { prednisolone } 30-400 \mathrm{mg} / \text { day, with continuation of } \\
\text { prednisolone at } 10 \mathrm{mg} / \text { day }\end{array}$ & Not reported & 42 \\
\hline Imatinib & SJS & $\begin{array}{l}\text { Recurrent with pruritic eruption at a lower dose of } 300 \mathrm{mg} / \\
\text { day, then tolerated after adding prednisolone at } 30 \mathrm{mg} / \text { day with } \\
\text { gradual tapering }\end{array}$ & & 43 \\
\hline Imatinib & SJS & $\begin{array}{l}\text { Recurrent with multiple pruritic vesicles and bullae suddenly } \\
\text { appeared after single-dose } 600 \mathrm{mg} / \text { day }\end{array}$ & Not reported & 89 \\
\hline Imatinib & SJS & $\begin{array}{l}\text { Recurrent with palpebral and labial edema with generalized } \\
\text { body rash after I-day rechallenge }\end{array}$ & Not reported & 123 \\
\hline Imatinib & DRESS & Recurrent erythematous skin rashes developed in 12 hours & & 124 \\
\hline Imatinib & DRESS & $\begin{array}{l}\text { Recurrent with periorbital edema, itching over face, and } \\
\text { eosinophilia after taking } 50 \% \text { dose }(200 \mathrm{mg}) \text {; however, } \\
\text { tolerated with combination of low-dose imatinib and oral } \\
\text { steroid }\end{array}$ & & 44 \\
\hline Imatinib & DRESS & & Nilotinib (tolerance) & 88 \\
\hline Imatinib & AGEP & Recurrent with urticaria & & 90 \\
\hline Ipilimumab & AGEP & Skin rashes got worse after second infusion & & 83 \\
\hline Sorafenib & SJS & Recurrent with pruritic erythematous eruptions and high fever & Not reported & 127 \\
\hline Sorafenib & AGEP & $\begin{array}{l}\text { Recurrent grouped pustules over the site close to previous } \\
\text { skin lesion }\end{array}$ & & 129 \\
\hline Vemurafenib & SJS & $\begin{array}{l}\text { Recurrent with rash and fever after taking } 50 \% \text { dose }(480 \mathrm{mg}) \\
\text { once, but tolerated with a program of desensitization with } \\
\text { dexamethasone }\end{array}$ & Not reported & 13 \\
\hline Vemurafenib & TEN & Not reported & $\begin{array}{l}\text { Lymphocyte transformation test } \\
\text { positive for vemurafenib with } \\
\text { cross-reactivity to dabrafenib and } \\
\text { sulfamethoxazole, but negative for } \\
\text { trametinib }\end{array}$ & 14 \\
\hline Vemurafenib & TEN & Not reported & $\begin{array}{l}\text { Dabrafenib (tolerance) with } \\
\text { gradual escalation }\end{array}$ & 70 \\
\hline
\end{tabular}

Abbreviations: AGEP, acute generalized exanthematous pustulosis; DRESS, drug rash with eosinophilia and systemic symptoms; SJS, Stevens-Johnson syndrome; TEN, toxic epidermal necrolysis. 
causality of vemurafenib and also showed positive crossreactivity for dabrafenib, but was negative for trametinib. This patient did not take dabrafenib or trametinib further. ${ }^{14}$

\section{Mortality}

A total of 14 patients died after SCAR episodes (Table 3): two SJS, one SJS/TEN, and 11 TEN. In total, the mortality of SJS/TEN was $26.9 \%$ (14 of 52) and higher in TEN cases (11 of $21,52.4 \%$ ). Seven patients died due to TEN reactions: six with progression of malignancies and one secondary to acute graft-versus-host disease of the gut. No mortality was seen in DRESS or AGEP cases. These cases were mostly treated with supportive care or immunosuppressants, including corticosteroids, cyclosporine, intravenous immunoglobulin, and TNF $\alpha$ inhibitors (etanercept and infliximab). One rituximab TEN case showed a good outcome after etanercept treatment. ${ }^{15}$ One nivolumab TEN case died 6 days after the onset of TEN due to septic shock and multisystem organ failure, despite treatment with infliximab, high-dose corticosteroids, intravenous immunoglobulin, and systemic antibiotics. ${ }^{16}$

Malignancy was an independently poor prognostic factor for patients with SJS/TEN. ${ }^{17-19}$ Several factors may contribute to poor prognosis in SJS/TEN patients with malignancies, including specific cancer types (hepatocellular carcinoma, colorectal cancer), chemotherapy, and malnutrition. ${ }^{19}$ The mortality rate from the reviewed TEN cases, 52.4\%, was higher than the average. ${ }^{4,5}$

\section{Prognosis and response to anticancer drugs after SCAR}

Interestingly, the occurrence of some adverse cutaneous reactions was found to have a positive correlation with the patient's response to treatment and overall survival (eg, EGFR inhibitors for patients with non-small-cell lung

Table 3 Mortality in severe cutaneous adverse reactions related to targeted anticancer therapies and immunotherapies ( $\mathrm{n}=\mathrm{I4})$

\begin{tabular}{|c|c|c|c|c|c|c|}
\hline Agent & Phenotype & Age/sex & Underlying disease & Cause of death & Latency & Reference \\
\hline Cetuximab & TEN & $74 /$ male & $\begin{array}{l}\text { Adenocarcinoma of the sigmoid } \\
\text { colon with hepatic metastasis }\end{array}$ & $\begin{array}{l}\text { Pneumonia with renal/respiratory } \\
\text { failure }\end{array}$ & 14 days & 6 \\
\hline Gefitinib & TEN & $\mathrm{U} / \mathrm{U}$ & $\begin{array}{l}\text { Non-small-cell lung cancer with } \\
\text { leptomeningeal metastases }\end{array}$ & Systemic lung cancer progression & 21 days & 113 \\
\hline Imatinib & SJS & $52 /$ male & Chronic myeloid leukemia & $\begin{array}{l}\text { Acute graft-versus-host disease } \\
\text { of the gut }\end{array}$ & 2 months & 121 \\
\hline Bortezomib & TEN & $6 \mathrm{I} / \mathrm{male}$ & IgG multiple myeloma & Multiorgan failure & 4 days & $|3|$ \\
\hline $\begin{array}{l}\text { Brentuximab } \\
\text { vedotin }\end{array}$ & TEN & 22/male & $\begin{array}{l}\text { Anaplastic large-cell lymphoma, } \\
\text { stage IIIA }\end{array}$ & Disease progression of lymphoma & 20 days & 138 \\
\hline Rituximab & SJS & $36 /$ male & Follicular non-Hodgkin's lymphoma & $\begin{array}{l}\text { Disease progression of } \\
\text { lymphoma with inferior vena cava } \\
\text { obstruction }\end{array}$ & 5 months & 134 \\
\hline Rituximab & SJS/TEN & 78/male & $\begin{array}{l}\text { Diffuse large B-cell lymphoma with } \\
\text { bone marrow involvement }\end{array}$ & $\begin{array}{l}\text { Died secondary to complications } \\
\text { of SJS/TEN }\end{array}$ & $\mathrm{U}$ & 63 \\
\hline Vemurafenib & TEN & $69 / \mathrm{male}$ & $\begin{array}{l}\text { Melanoma with axillary lymph } \\
\text { nodes and pulmonary metastasis }\end{array}$ & Sepsis & 4 days & 139 \\
\hline Vemurafenib & TEN & 63/female & $\begin{array}{l}\text { Melanoma with cervical lymph- } \\
\text { node, scalp, lung, and liver } \\
\text { metastases }\end{array}$ & Disease progression of melanoma & 3 months & 68 \\
\hline Vemurafenib & TEN & 73/female & $\begin{array}{l}\text { Melanoma with inguinal lymph node } \\
\text { metastasis }\end{array}$ & $\begin{array}{l}\text { Multiple-organ failure after } \\
\text { ventilator-acquired pneumonia } \\
\text { and melena }\end{array}$ & 35 days & 142 \\
\hline Aldesleukin & TEN & $67 /$ female & $\begin{array}{l}\text { Renal cell carcinoma with lung } \\
\text { metastasis }\end{array}$ & $\begin{array}{l}\text { Septic shock and hypovolemia } \\
\text { secondary to pancytopenia and } \\
\text { TEN }\end{array}$ & 10 days & 77 \\
\hline Denileukin & TEN & $45 / \mathrm{male}$ & $\begin{array}{l}\text { Follicular large-cell lymphoma with } \\
\text { widespread lymphadenopathy, } \\
\text { splenomegaly, and bone marrow } \\
\text { involvement }\end{array}$ & $\begin{array}{l}\text { Multisystem organ failure } \\
\text { with massive TEN and disease } \\
\text { progression of lymphoma }\end{array}$ & 18 days & 75 \\
\hline Nivolumab & TEN & $64 /$ female & $\begin{array}{l}\text { Melanoma with pulmonary and liver } \\
\text { metastases }\end{array}$ & $\begin{array}{l}\text { Disease progression of melanoma } \\
\text { and sepsis }\end{array}$ & 4 months & 79 \\
\hline Nivolumab & TEN & $50 /$ female & Metastatic malignant melanoma & $\begin{array}{l}\text { Septic shock and multisystem } \\
\text { organ failure }\end{array}$ & 6 days & 81 \\
\hline
\end{tabular}


cancer, and nivolumab or pembrolizumab for patients with melanoma). ${ }^{20-22}$ However, the possible connection between treatment response to anticancer therapies and SCAR reactions remains not fully defined. Only eight of 16 reported cases $(50 \%)$ showed positive clinical responses to causative anticancer drugs, including three with complete remission and five with partial response (Table 1). Most patients discontinued causative agents for SCAR reactions to prevent possible recurrence of this deadly condition. This limited the assessment for the prognostic significance of SCAR related to anticancer agents.

\section{Stevens-Johnson syndrome/toxic epidermal necrolysis EGFR inhibitors}

EGFRs are a large family of receptor tyrosine kinases expressed in several types of cancers, including non-smallcell lung, colorectal, breast, pancreatic, head-and-neck, and esophageal cancers. ${ }^{23,24}$ Clinical use of EGFR-targeted therapies has been approved for treating various cancers. ${ }^{23,24}$ Despite the benefits, EGFR inhibitors cause enormous cutaneous adverse drug reactions (ADRs) with incidence up to $80 \% .{ }^{25}$ EGFR inhibitor-induced cutaneous ADRs are present in a broad spectrum, including papulopustular eruptions, mucositis, photosensitivity, xerosis, and paronychia. ${ }^{1}$ In addition, EGFR inhibitors can induce fatal SCARs, initially mimicking mucositis or papulopustular eruptions, including SJS/TEN, DRESS, and AGEP. ${ }^{26,27}$ From the literature search, five SJS, two SJS/TEN, and five TEN cases induced by EGFR inhibitors were reported in total. In spite of being rare, SJS/ TEN should be distinguished from EGFR inhibitor-related mucositis if mucosal lesions are accompanied by fever, constitutional symptoms, and severe painful erythema or blisters noted over mucosa and skin as well. Skin eruptions with SJS/ TEN usually present as erythematous spots progressing into painful targetoid erythema with truncal distribution, which is different from the papulopustular eruption induced by EGFR inhibitors. ${ }^{25,28}$ Three patients have been found to have cross-reactivity to alternative EGFR inhibitors, although one report showed successful treatment with gefitinib in an afatinib SJS patient with adenocarcinoma of the lung. ${ }^{29}$ The pathomechanism underlying EGFR inhibitor-induced SJS/ TEN could be due to interference of epidermal differentiation and re-epithelialization by the irreversible inhibition of EGFR, ultimately resulting in extensive erosions. This is different from typical SJS/TEN, which is a delay-type hypersensitivity reaction where cytotoxic $\mathrm{T}$ cells generate and release granulysin, a cytotoxic protein responsible for disseminated keratinocyte death. ${ }^{30,31}$ In one reported case of afatinib SJS, the patient had no sign of fever, no ocular and genital mucosae affected, and no obvious epidermal necrosis detected histopathologically, which is inconsistent with typical SJS ${ }^{30}$ As such, the diagnosis and pathophysiology of EGFR inhibitor-induced SJS/TEN need further elucidation.

\section{KIT and BCR-ABL inhibitors}

KIT and BCR-ABL inhibitors, such as imatinib, nilotinib, and dasatinib, are tyrosine kinase inhibitors used for the treatment of Philadelphia chromosome-positive chronic myeloid leukemia and gastrointestinal stromal tumors. ${ }^{32-34}$ Their utilization has extended to different tumors and accomplished a first-line position in cancers like Philadelphia chromosomepositive acute lymphoblastic leukemia, advanced dermatofibrosarcoma protuberans, hypereosinophilic syndrome, and systemic mastocytosis. ${ }^{35}$ Among these agents, imatinib is the major targeted anticancer drug to induce SCARs, including twelve SJS/TEN, four DRESS, and four AGEP. Cutaneous adverse effects of imatinib are common and have been well described. Of these, maculopapular rashes and facial edema occur most commonly, with incidence of $66.7 \%$ and $65.0 \%$, respectively. ${ }^{36}$ Maculopapular rashes usually develop on average about 9 weeks after initiation. The incidence of cutaneous reactions with imatinib has been reported to increase with escalating doses of the drug, indicating that these conditions may be related to the pharmacologic effects of the drug, rather than to hypersensitivity. ${ }^{37}$ Besides, in one multivariate analysis, female sex and daily dose of imatinib were independent risk factors for the development of rashes. ${ }^{36}$ These cutaneous events with dose-dependent manifestations may need temporary discontinuation or dose reduction. ${ }^{1}$ Moreover, the pathomechanism of SJS and DRESS is immunorelated, and further rechallenge with a dose reduction is not usually suggested. ${ }^{38,39}$ However, several cases have been tolerated well under slow titration with or without prednisolone use. ${ }^{40-44}$

\section{Multikinase inhibitors}

Multikinase inhibitors are small-molecule inhibitors of VEGF tyrosine kinase and also inhibit other tyrosine kinases (PDGFR, EGFR, KIT, Ret, FLT3, CSF1R, and Raf). ${ }^{45}$ This class of agents, including sorafenib, sunitinib, pazopanib, regorafenib, and vandetanib, has been approved for the treatment of patients with renal cell cancer, gastrointestinal stromal tumors, hepatocellular cancer, and colorectal cancer. ${ }^{46}$ These drugs often cause notorious hand-foot skin reactions and other skin eruptions, such as maculopapular eruptions, stomatitis, and genital erosions. ${ }^{47-49}$ Among these medica- 
tions, higher frequency of cutaneous toxicity has been found in patients using sorafenib. ${ }^{1}$ Hand-foot skin reactions are severe, painful edematous erythema lesions on the palms and soles, and even progression with blistering or hyperkeratotic plaques. ${ }^{49}$ Skin eruptions with variable morphology have been reported, particularly morbilliform eruptions in the early weeks after initiation. ${ }^{1}$ The infrequent genital or perineal involvement with erosion is also characteristic of multikinase inhibitor-related ADRs, and this manifestation should be distinguished from SJS or fixed drug eruptions. ${ }^{1,48,50}$ Based on the literature search, three sorafenib SJS/TEN and three sorafenib AGEP cases have been reported. One patient who restarted sorafenib treatment for 2 weeks after administration of sorafenib for 1.5 years and then a temporal discontinuation for 1 month suffered from TEN. ${ }^{51}$ Considering that SJS/ TEN is a delayed-type hypersensitivity, sensitization of 1.5 years could be too long. Further, the authors proposed that the concomitant oral tosufloxacin may have contributed to the development of the skin manifestation by inhibiting sorafenib metabolism, since both drugs are metabolized by cytochrome P450 family enzymes in the liver. ${ }^{51}$ The pathogenesis involved in the cutaneous toxicity due to multikinase inhibitors is believed to be related to direct VEGF inhibition, vessel regression, and negative effects on vascular repair capacities. ${ }^{52}$ Furthermore, our previous study has revealed that keratinocyte death in sunitinib-induced hand-foot skin reaction was mediated via Fas/FasL. ${ }^{53}$ Recently, Zimmerman et al demonstrated a pathway by which sorafenib enters keratinocytes through OAT6 (an uptake carrier of sorafenib) and then causes keratinocyte cytotoxicity driven by inhibition of MAP3K7 (Tak1). ${ }^{54}$ These predisposing factors can promote skin toxicity once severe epidermal necrolysis occurs in patients who used this class of medications and delay wound healing. Moreover, the incidence of sorafenib-induced erythema multiforme is much higher in Japanese patients than in white populations. ${ }^{55}$ It could be reasonable to speculate that genetic background in different ethnicities may play a role in the pathogenesis of this ADR.

\section{Monoclonal antibodies to CD20}

Rituximab is a chimeric (mouse-human) monoclonal antibody to target $\mathrm{CD} 20^{+}$blood cells for treating non-Hodgkin lymphoma, chronic lymphocytic leukemia, and some autoimmune diseases, such as pemphigus, bullous pemphigoid, and rheumatoid arthritis. ${ }^{56-58}$ There were two SJS, two SJS-TEN, and one TEN caused by rituximab in several case reports. The diagnosis of SJS from one previously published case report might have been erroneously associated with rituximab, since the clinical presentation, histopathology, and nature course in the case report were mimicking paraneoplastic pemphigus (PNP). ${ }^{59}$ PNP is a fatal mucocutaneous blistering disorder associated with hematologic malignancies. ${ }^{60}$ PNP shares overlapping clinical features with SJS, including severe mucositis, flaccid sloughing bullae, keratinocyte necrosis histopathologically, and possible pulmonary involvement with features of bronchiolitis obliterans. ${ }^{61}$ Nevertheless, refractory chronic mucositis with polymorphous PNP skin lesions is different from an acute, rapidly progressing course with targetoid lesions of SJS/TEN. Typical histopathological features with suprabasal acantholysis, lichenoid interface dermatitis, positive DIF/IIF, and immunoblotting recognition of envoplakin and/or periplakin can support a diagnosis of PNP. $^{61,62}$ In cases of suspicious rituximab SJS/TEN, DIF or IIF has been suggested to exclude PNP. ${ }^{59}$ Moreover, rituximab is usually prescribed with concomitant bendamustine or allopurinol, which adds a difficulty to assessing causality. In five rituximab SJS/TEN, three cases were independent from the use of bendamustine or allopurinol. Also, seven rituximab TEN cases have been reported without concomitant allopurinol, bendamustine, or nonbendamustine chemotherapy based on the US Food and Drug Administration adverse event reporting system. ${ }^{63}$

\section{BRAF inhibitors}

BRAF inhibitors, including vemurafenib and dabrafenib, have emerged as a remarkable anticancer therapy and improved the survival of melanoma patients carrying $B R A F^{\mathrm{v} 600 \mathrm{E} / \mathrm{K}} \cdot{ }^{64}$ Cutaneous adverse events induced by BRAF inhibitors vary from skin eruptions with photosensitivity, folliculocentric morbilliform eruptions, hyperkeratotic hand-foot skin reactions, and panniculitis to secondary epidermal neoplasms (verrucal keratoses, squamous-cell carcinoma, and keratoacanthoma). ${ }^{65-67}$ In our survey, vemurafenib was the most notorious drug to cause TEN among the anticancer-targeted drugs. Of note, one case with vemurafenib-induced TEN was reported after nivolumab failure and another with vemurafenib SJS after initiation of ipilimumab. ${ }^{13,68}$ Development of grade 3 rash was found to be significantly higher with vemurafenib treatment after administration of ipilimumab. ${ }^{69}$ The reduction in immunocheckpoint inhibition may predispose patients to skin hypersensitivity reactions caused by vemurafenib. ${ }^{69}$ This phenomenon might be explained by immunocheckpoint inhibitor strongly provoking activation of $\mathrm{CD}^{+}$cytotoxic $\mathrm{T}$ cells, which are also the key cellular mediators in SJS/TEN. In addition, biopsy of skin metastases during nivolumab 
treatment has also shown evidence of $\mathrm{CD}^{+} \mathrm{T}$-cell infiltrations. ${ }^{68} \mathrm{~A}$ successful switch from vemurafenib to dabrafenib has been reported in one vemurafenib TEN patient. ${ }^{70}$ Dabrafenib may thus be considered a relatively newer and safer alternative treatment option for vemurafenib. However, another vemurafenib TEN patient who underwent an LTT assay confirmed the causality of vemurafenib and positive cross-reactivity for dabrafenib. ${ }^{14}$ Besides, crossreactivity has also been found between vemurafenib and the sulfonamide antibiotic sulfamethoxazole, but not seen in trametinib. ${ }^{14}$ Based on the cross-reactivity reaction due to structural similarity between the drug with sulfonamide compounds, such as sulfamethoxazole and vemurafenib or dabrafenib, the use of sulfonamide compounds in patients with vemurafenib S CAR was not suggested.

\section{Immunooncology therapies}

Immunotherapies are developing innovative therapeutics with significant advances in treatment for melanoma, nonsmall-cell lung cancer, and renal cell carcinoma, etc. ${ }^{71-73}$ Therapeutic monoclonal antibodies targeting the coinhibitory immunocheckpoint have been associated with vitiligo, pruritus, morbilliform eruptions, lichenoid dermatitis, delayed type hypersensitivity, and autoimmune bullous disease. ${ }^{74}$ Although uncommon, SJS/TEN related to anti-PD1 (nivolumab and pembrolizumab) and anti-CTLA4 (ipilimumab) has also been reported. In total, three SJS/TEN cases associated with conventional immunotherapies (recombinant IL2) - aldesleukin $(n=2)$ and denileukin $(n=1)$ - were described. ${ }^{75-77}$ For newly developed immunotherapies, there have been nivolumab TEN, four pembrolizumab SJS, one ipilimumab SJS, and one ipilimumab TEN case. ${ }^{78-84}$ These patients were diagnosed with advanced metastatic melanoma, metastatic nasopharyngeal carcinoma, and metastatic sarcomatoid renal cell carcinoma. The drug latency to induce SJS/TEN varied from 7 days to 140 days. Two melanoma patients suffered from morbilliform eruption and progressed to TEN over 39 days to 3 months after receiving nivolumab treatment. ${ }^{16,78}$ Initial biopsy of these two nivolumab TEN cases showed interface dermatitis that further progressed into full-thickness epidermal necrosis. ${ }^{16}$ By immunohistochemistry staining, increased expression of PDL1 was evident on skin-infiltrating $\mathrm{T}$ cells and keratinocytes at foci of lymphocytic epidermal infiltration in the epidermis. ${ }^{16,79}$ PDL1 is not usually detectable in skin, but the use of anti-PD1 therapy could increase the expression of PDL1 in keratinocytes and permit the activated $\mathrm{CD} 8^{+}$cytotoxic $\mathrm{T}$ cells to target keratinocytes, leading to keratinocyte apoptosis. ${ }^{79}$ Notably, the gene expression profile of anti-PD1-induced adverse cutane- ous eruption was similar to that of SJS/TEN, but different from that of acute cutaneous graft-versus-host disease or maculopapular rashes. ${ }^{79}$ Anti-PD1-treated patients and SJS/ TEN patients shared similar gene expression profiles, with upregulation of major inflammatory chemokines, including CXCL9, CXCL10, and CXCL11, cytotoxic mediators, such as PRF1 and GZMB, and the proapoptotic molecule FASLG. ${ }^{79}$ Bullous pemphigoid, an autoimmune bullous mucocutaneous disease, induced after initiation of immunotherapy has also been reported. ${ }^{85}$ To clarify further, a diagnosis of SJS/TEN, DIF or IIF can help eliminate the possibility of autoimmune bullous diseases.

\section{Drug rash with eosinophilia and systemic symptoms/drug-induced hypersensitivity syndrome}

Although relatively rare, nine cases of DRESS/DIHS caused by imatinib $(n=4)$, vemurafenib $(n=3)$, bortezomib $(n=1)$, and ipilimumab $(n=1)$ have been reported. Many targeted anticancer drugs, including KIT, BCR-ABL inhibitors, multikinase inhibitors, BRAF inhibitors, MEK inhibitors, CTLA4 inhibitors, and PL1 inhibitors, can result in aspecific maculopapular eruptions. ${ }^{1,86}$ Distinguishing maculopapular rashes from DRESS is important, mainly because there are prognostic differences. Concomitant generalized maculopapular rashes with facial edema could overlap characteristics of DRESS, but the lack of systemic involvement with fever, eosinophilia, atypical lymphocytosis, and hepatic or renal function impairment can help distinguish from DRESS. ${ }^{9,87}$ Typically, the cutaneous manifestation of DRESS progresses from maculopapular exanthema into infiltrative erythema and purpuric changes beyond lower extremities.

\section{Acute generalized exanthematous pustulosis}

In our search, 11 cases of AGEP caused by imatinib $(n=4)$, sorafenib $(n=3)$, gefitinib $(n=2)$, vemurafenib $(n=1)$, and ipilimumab $(n=1)$ were identified. ${ }^{88-91}$ AGEP usually presents as pinhead-sized "nonfollicular" pustules on an erythematous base, starting mainly on the fold area (axillary, inguinal, and submammary) and spreading quickly to the trunk and limbs with further characteristic large-sheet collaret desquamation. ${ }^{92}$ AGEP should be differentiated from the common acneiform papulopustular eruptions caused by EGFR inhibitors. It is characteristic of a "folliculocentric" erythematous papule or pustule with dominant distribution in sebaceous gland-rich areas, such as the scalp, face, upper trunk..$^{93}$ Although the acneiform eruption caused by EGFR inhibitors may involve 
the lower trunk, buttocks, and extremities, histopathology can help to distinguish between these two entities. The major histopathologic findings of acneiform eruption are superficial suppurative folliculitis with neutrophilic infiltrate with ectatic follicular infundibula and rupture of the epithelial lining. ${ }^{94}$ In contrast, AGEP typically shows subcorneal and/ or intraepithelial pustules, an edematous papillary dermis with exocytosis, and perivascular infiltrates of neutrophils and eosinophils. ${ }^{95,96}$ Occasionally, dyskeratosis or necrosis of keratinocytes can be seen in AGEP. ${ }^{97}$ In addition, systemic manifestation with fever and neutrophilia require attention to be paid to AGEP, and further short-term topical and corticosteroid treatment may be considered. ${ }^{98}$

\section{Simultaneous predisposing factors}

About one-third of reported cases have been exposed to multiple medications during the same period o of anticancer-targeted therapies (Table 4). Among these medications, there were some notorious drugs to cause SCARs, including allopurinol, phenytoin, and sulfamethoxazole. Multiple concomitant medications increase complexities and difficulties in identifying the offending medication. The Naranjo score and algorithm of drug causality in epidermal necrolysis are considered the standard assessment tools to evaluate the causality of ADRs and SJS/TEN, respectively. ${ }^{99,100}$ Few cases reported in the literature were evaluated by these scoring algorithms. In addition, the use of multiple medications increased the risk of ADRs and also for pharmacokinetic and pharmacodynamic drug interactions. ${ }^{101,102}$ Moreover, several predisposing factors were discussed in this review. One patient developed erlotinib SJS after herpes zoster superinfection. ${ }^{26}$ Exposure to radiation was a common factor seen in cancer patients with SJS/TEN ${ }^{2}$ There was one cetuximab SJS/TEN overlapping with radiotherapy for squamous cell carcinoma of the hypopharynx and larynx and two pembrolizumab SJS patients received radiotherapy before skin eruption (one with whole-brain radiotherapy and concomitant phenytoin use and the other with radiotherapy for bone metastases). ${ }^{80,84,103}$ Moreover, the initiation of immunocheckpoint inhibitors may also predispose patients to skin hypersensitivity reactions and SJS/TEN. ${ }^{13,68,69,104}$

Table 4 Targeted anticancer therapies and immunotherapy-induced severe cutaneous adverse reaction cases with multiple concomitant medication $(n=24)$

\begin{tabular}{|c|c|c|c|}
\hline Agent & Coadministered medication & Phenotype & Reference \\
\hline Afatinib & Carboplatin, pemetrexed, esomeprazole, and sulfamethoxazole & SJS & 30 \\
\hline Brentuximab vedotin & Naproxen & SJS & 137 \\
\hline Brentuximab vedotin & Piperacillin-tazobactam, omeprazole, morphine, granisetron, pregabalin, and amisulpride & TEN & 138 \\
\hline Cetuximab & Minocycline & TEN & 111 \\
\hline Cetuximab & Camptothecin-II & SJS & 112 \\
\hline Gefitinib & Pemetrexed and cisplatin & TEN & 114 \\
\hline Imatinib & Ibuprofen & SJS & 117 \\
\hline Imatinib & Mercaptopurine & SJS & 42 \\
\hline Imatinib & Allopurinol and sulfamethoxazole-trimethoprim & SJS & 89 \\
\hline Imatinib & Fludarabine, busulfan & SJS & 121 \\
\hline Imatinib & Allopurinol & SJS & 122 \\
\hline Imatinib & Lansoprazole & SJS & 123 \\
\hline Imatinib & Allopurinol & DRESS & 124 \\
\hline Pembrolizumab & $\begin{array}{l}\text { Phenprocoumon, spironolactone, acetylsalicylic acid, bisoprolol, metamizole, rabeprazole, } \\
\text { mirtazapine, lorazepam, torasemide, ramipril, oxycodone, and dalteparin }\end{array}$ & SJS & 80 \\
\hline Pembrolizumab & Phenytoin (with whole-brain radiotherapy) & SJS & 81 \\
\hline Rituximab & Bendamustine & SJS/TEN & 135 \\
\hline Rituximab & Allopurinol and bendamustine & SJS/TEN & 63 \\
\hline Sorafenib & Tosufloxacin & TEN & 51 \\
\hline Sorafenib & Furosemide, spironolactone, and lansoprazole & AGEP & 129 \\
\hline Vemurafenib & Ipilimumab & SJS & 13 \\
\hline Vemurafenib & Valproate & TEN & 142 \\
\hline Vemurafenib & Levothyroxine sodium & TEN & 68 \\
\hline Vemurafenib & Metoprolol and hydrochlorothiazide & DRESS & 144 \\
\hline Vandetanib & Temozolomide & TEN & 116 \\
\hline
\end{tabular}

Abbreviations: AGEP, acute generalized exanthematous pustulosis; DRESS, drug rash with eosinophilia and systemic symptoms; SJS, Stevens-Johnson syndrome; TEN, toxic epidermal necrolysis. 


\section{Causative drug validation}

To confirm a potential offending drug, drug provocation is a gold standard. However, rechallenge is generally avoided, because of the potentially fatal consequences. Clinically, the drug notoriety scoring systems, including Naranjo score and algorithm of drug causality in epidermal necrolysis (for SJS/ TEN only), have been implemented to assess the causality of ADRs. ${ }^{99}{ }^{100}$ In vitro, a positive LTT is helpful for identifying causality and cross-reactivity. ${ }^{105}$ The LTT is a reproducible test that measures enhanced proliferative response of peripheral blood mononuclear cells after sensitization of $\mathrm{T}$ cells to a drug. ${ }^{105}$ Its relevance in DRESS/DIHS and AGEP is relatively higher than in SJS/TEN. ${ }^{106}$ To avoid cross-reactivity in patients with a history of severe hypersensitivity reactions to medications with similar structures, an LTT may be considered before prescription. It is worth mentioning that sensitivity varies with diverse drugs and different timing among studies, and a negative result does not rule out the possibility of reactivity or cross-reactivity. ${ }^{106,107}$ After an LTT, no evidence for a drug-specific immunoresponse to concomitant medication was revealed in one pembrolizumab SJS case. ${ }^{79}$ Moreover, in vivo patch tests may also provide a low-risk method to validate delayed hypersensitivity with suspected offending drugs or alternative drugs. ${ }^{108}$

\section{Conclusion}

SCARs are potentially life-threatening cutaneous adverse events in patients treated with targeted anticancer drugs and immunotherapies. Patients with malignancies usually have additional comorbidities, multisystemic involvement, and multiple concomitant medications and treatment modalities, all of which may increase the complexities and difficulties in managing SCARs in cancer patients. It is important to recognize SCAR reactions earlier, distinguish SCARs from other nonfatal dermatologic toxicities, and discontinue causative agents rapidly. Further studies are needed to investigate specific pathomechanisms and develop proper management for this lethal disease in particular in these high-risk cancer patients.

\section{Author contributions}

All authors contributed toward data analysis, drafting and critically revising the paper, gave final approval of the version to be published, and agree to be accountable for all aspects of the work.

\section{Acknowledgments}

This work was supported by research grants from the Ministry of Science and Technology, Taiwan (MOST
104-2314-B-182A-151-MY2) to SCS and Chang Gung Memorial Hospital, Keelung, Taiwan (CMRPG2H0081) to CBC.

\section{Disclosure}

The authors report no conflicts of interest in this work.

\section{References}

1. Macdonald JB, Macdonald B, Golitz LE, LoRusso P, Sekulic A. Cutaneous adverse effects of targeted therapies - part I: inhibitors of the cellular membrane. J Am Acad Dermatol. 2015;72(2):203-220.

2. Rosen AC, Balagula Y, Raisch DW, et al. Life-threatening dermatologic adverse events in oncology. Anticancer Drugs. 2014;25(2):225-234

3. Phillips EJ, Chung WH, Mockenhaupt M, Roujeau JC, Mallal SA. Drug hypersensitivity: pharmacogenetics and clinical syndromes. $J$ Allergy Clin Immunol. 2011;127(3 Suppl):S60-S66.

4. Roujeau JC, Stern RS. Severe adverse cutaneous reactions to drugs. N Engl J Med. 1994;331(19):1272-1285.

5. Roujeau JC, Guillaume JC, Fabre JP, Penso D, Fléchet ML, Girre JP. Toxic epidermal necrolysis (Lyell syndrome): incidence and drug etiology in France, 1981-1985. Arch Dermatol. 1990;126(1):37-42.

6. Lin WL, Lin WC, Yang JY, et al. Fatal toxic epidermal necrolysis associated with cetuximab in a patient with colon cancer. J Clin Oncol. 2008;26(16):2779-2780.

7. Schwartz RA, McDonough PH, Lee BW. Toxic epidermal necrolysis - part II: prognosis, sequelae, diagnosis, differential diagnosis, prevention, and treatment. JAm Acad Dermatol. 2013;69(2):187.e1-e16; quiz 203-204.

8. Kardaun SH, Sidoroff A, Valeyrie-Allanore L, et al. Variability in the clinical pattern of cutaneous side-effects of drugs with systemic symptoms: does a DRESS syndrome really exist? $\mathrm{Br} J$ Dermatol. 2007;156(3):609-611.

9. Cacoub P, Musette P, Descamps V, et al. The DRESS syndrome: a literature review. Am J Med. 2011;124(7):588-597.

10. Kardaun SH, Sekula P, Valeyrie-Allanore L, et al. Drug reaction with eosinophilia and systemic symptoms (DRESS): an original multisystem adverse drug reaction: results from the prospective RegiSCAR study. Br J Dermatol. 2013;169(5):1071-1080.

11. Sidoroff A, Dunant A, Viboud C, et al. Risk factors for acute generalized exanthematous pustulosis (AGEP): results of a multinational case-control study (EuroSCAR). Br J Dermatol. 2007;157(5):989-996.

12. Gey A, Milpied B, Dutriaux C, et al. Severe cutaneous adverse reaction associated with vemurafenib: DRESS, AGEP or overlap reaction? J Eur Acad Dermatol Venereol. 2016;30(1):178-179.

13. Minor DR, Rodvien R, Kashani-Sabet M. Successful desensitization in a case of Stevens-Johnson syndrome due to vemurafenib. Melanoma Res. 2012;22(5):410-411.

14. Bellon T, Lerma V, Gonzalez-Valle O, Herrada CG, de Abajo FJ. Vemurafenib-induced toxic epidermal necrolysis: possible crossreactivity with other sulfonamide compounds. $\mathrm{Br} J$ Dermatol. 2016;174(3):621-624.

15. Didona D, Paolino G, Garcovich S, Caro RD, Didona B. Successful use of etanercept in a case of toxic epidermal necrolysis induced by rituximab. J Eur Acad Dermatol Venereol. 2016;30(10):e83-e84.

16. Vivar KL, Deschaine M, Messina J, et al. Epidermal programmed cell death-ligand 1 expression in TEN associated with nivolumab therapy. J Cutan Pathol. 2017;44(4):381-384.

17. Bastuji-Garin S, Fouchard N, Bertocchi M, Roujeau JC, Revuz J, Wolkenstein P. SCORTEN: a severity-of-illness score for toxic epidermal necrolysis. J Invest Dermatol. 2000;115(2):149-153.

18. Guegan S, Bastuji-Garin S, Poszepczynska-Guigne E, Roujeau JC, Revuz J. Performance of the SCORTEN during the first five days of hospitalization to predict the prognosis of epidermal necrolysis. J Invest Dermatol. 2006;126(2):272-276. 
19. Wu J, Lee YY, Su SC, et al. Stevens-Johnson syndrome and toxic epidermal necrolysis in patients with malignancies. Br J Dermatol. 2015;173(5):1224-1231.

20. Liu HB, Wu Y, Lv TF, et al. Skin rash could predict the response to EGFR tyrosine kinase inhibitor and the prognosis for patients with non-small cell lung cancer: a systematic review and meta-analysis. PLoS One. 2013;8(1):e55128.

21. Sanlorenzo M, Vujic I, Daud A, et al. Pembrolizumab cutaneous adverse events and their association with disease progression. JAMA Dermatol. 2015;151(11):1206-1212.

22. Freeman-Keller M, Kim Y, Cronin H, Richards A, Gibney G, Weber JS. Nivolumab in resected and unresectable metastatic melanoma: characteristics of immune-related adverse events and association with outcomes. Clin Cancer Res. 2016;22(4):886-894.

23. Seshacharyulu P, Ponnusamy MP, Haridas D, Jain M, Ganti AK, Batra SK. Targeting the EGFR signaling pathway in cancer therapy. Expert Opin Ther Targets. 2012;16(1):15-31.

24. Yewale C, Baradia D, Vhora I, Patil S, Misra A. Epidermal growth factor receptor targeting in cancer: a review of trends and strategies. Biomaterials. 2013;34(34):8690-8707.

25. Lacouture ME, Anadkat MJ, Bensadoun RJ, et al. Clinical practice guidelines for the prevention and treatment of EGFR inhibitor-associated dermatologic toxicities. Support Care Cancer. 2011;19(8):1079-1095.

26. Wnorowski AM, de Souza A, Chachoua A, Cohen DE. The management of EGFR inhibitor adverse events: a case series and treatment paradigm. Int J Dermatol. 2012;51(2):223-232.

27. Liquete E, Ali S, Kammo R, et al. Acute Generalized exanthematous pustulosis induced by erlotinib (Tarceva) with superimposed Staphylococcus aureus skin infection in a pancreatic cancer patient: a case report. Case Rep Oncol. 2012;5(2):253-259.

28. Bastuji-Garin S, Rzany B, Stern RS, Shear NH, Naldi L, Roujeau JC. Clinical classification of cases of toxic epidermal necrolysis, Stevens-Johnson syndrome, and erythema multiforme. Arch Dermatol. 1993;129(1):92-96.

29. Otsuka T, Tanaka A, Azukizawa H, et al. Successful treatment with gefitinib after Stevens-Johnson syndrome associated with afatinib therapy in a patient with adenocarcinoma of the lung. Int Cancer Conf J. 2017;6(1):38-41.

30. Honda Y, Hattori Y, Katsura S, et al. Stevens-Johnson syndromelike erosive dermatitis possibly related to afatinib. Eur J Dermatol. 2016;26(4):413-414.

31. Chung WH, Hung SI, Yang JY, et al. Granulysin is a key mediator for disseminated keratinocyte death in Stevens-Johnson syndrome and toxic epidermal necrolysis. Nat Med. 2008;14(12):1343-1350.

32. Druker BJ, Guilhot F, O’Brien SG, et al. Five-year follow-up of patients receiving imatinib for chronic myeloid leukemia. $N$ Engl J Med. 2006;355(23):2408-2417.

33. Casali PG, Le Cesne A, Velasco AP, et al. Imatinib failure-free survival (IFS) in patients with localized gastrointestinal stromal tumors (GIST) treated with adjuvant imatinib (IM): the EORTC/AGITG/FSG/GEIS/ISG randomized controlled phase III trial. J Clin Oncol. 2013;31(15 Suppl):10500.

34. Leonetti F, Stefanachi A, Nicolotti O, et al. BCR-ABL inhibitors in chronic myeloid leukemia: process chemistry and biochemical profile. Curr Med Chem. 2011;18(19):2943-2959.

35. Iqbal N, Iqbal N. Imatinib: a breakthrough of targeted therapy in cancer. Chemother Res Pract. 2014;2014:357027.

36. Valeyrie L, Bastuji-Garin S, Revuz J, et al. Adverse cutaneous reactions to imatinib (STI571) in Philadelphia chromosome-positive leukemias: a prospective study of 54 patients. J Am Acad Dermatol. 2003;48(2):201-206

37. Brouard M, Saurat JH. Cutaneous reactions to STI571. NEngl J Med. 2001;345(8):618-619.

38. White KD, Chung WH, Hung SI, Mallal S, Phillips EJ. Evolving models of the immunopathogenesis of T cell-mediated drug allergy: the role of host, pathogens, and drug response. JAllergy Clin Immunol. 2015;136(2):219-234.
39. Duong TA, Valeyrie-Allanore L, Wolkenstein P, Chosidow O. Severe cutaneous adverse reactions to drugs. Lancet. 2017;390(10106): 1996-2011.

40. Mahapatra M, Mishra P, Kumar R. Imatinib-induced Stevens-Johnson syndrome: recurrence after re-challenge with a lower dose. Ann Hematol. 2007;86(7):537-538.

41. Pavithran K, Thomas M. Imatinib induced Stevens-Johnson syndrome: lack of recurrence following re-challenge with a lower dose. Indian J Dermatol Venereol Leprol. 2005;71(4):288-289.

42. Sanchez-Gonzalez B, Pascual-Ramirez JC, Fernandez-Abellan P, Belinchon-Romero I, Rivas C, Vegara-Aguilera G. Severe skin reaction to imatinib in a case of Philadelphia-positive acute lymphoblastic leukemia. Blood. 2003;101(6):2446.

43. Rule SA, O’Brien SG, Crossman LC. Managing cutaneous reactions to imatinib therapy. Blood. 2002;100(9):3434-3435.

44. Kumar M, Mandal PK, Dolai TK, Bhattacharrya M. Imatinib causing drug rash with eosinophilia and systemic symptoms: a rare cutaneous reaction. Indian Dermatol Online J. 2014;5(Suppl 2):S120-S122.

45. Gotink KJ, Verheul HM. Anti-angiogenic tyrosine kinase inhibitors: what is their mechanism of action? Angiogenesis. 2010;13(1):1-14.

46. Jeong W, Doroshow JH, Kummar S. United States Food and Drug Administration approved oral kinase inhibitors for the treatment of malignancies. Curr Probl Cancer. 2013;37(3):110-144.

47. Ishak RS, Aad SA, Kyei A, Farhat FS. Cutaneous manifestations of anti-angiogenic therapy in oncology: review with focus on VEGF inhibitors. Crit Rev Oncol Hematol. 2014;90(2):152-164.

48. Billemont B, Barete S, Rixe O. Scrotal cutaneous side effects of sunitinib. N Engl J Med. 2008;359(9):975-976.

49. Chanprapaph K, Rutnin S, Vachiramon V. Multikinase inhibitor-induced hand-foot skin reaction: a review of clinical presentation, pathogenesis, and management. Am J Clin Dermatol. 2016;17(4):387-402.

50. Gupta V, Rao A, Gupta S. Scrotal cutaneous toxicity: an uncommon but important side-effect of sunitinib. J Eur Acad Dermatol Venereol. 2016;30(1):132-133.

51. Choi MK, Woo HY, Heo J, et al. Toxic epidermal necrolysis associated with sorafenib and tosufloxacin in a patient with hepatocellular carcinoma. Ann Dermatol. 2011;23(Suppl 3):S404-S407.

52. Blanchet B, Billemont B, Barete S, et al. Toxicity of sorafenib: clinical and molecular aspects. Expert Opin Drug Saf. 2010;9(2):275-287.

53. Yeh CN, Chung WH, Su SC, et al. Fas/Fas ligand mediates keratinocyte death in sunitinib-induced hand-foot skin reaction. J Invest Dermatol. 2014;134(11):2768-2775.

54. Zimmerman EI, Gibson AA, Hu S, et al. Multikinase inhibitors induce cutaneous toxicity through OAT6-mediated uptake and MAP3K7driven cell death. Cancer Res. 2016;76(1):117-126.

55. Ikeda M, Fujita T, Amoh Y, Mii S, Matsumoto K, Iwamura M. StevensJohnson syndrome induced by sorafenib for metastatic renal cell carcinoma. Urol Int. 2013;91(4):482-483.

56. Reff ME, Carner K, Chambers KS, et al. Depletion of B cells in vivo by a chimeric mouse human monoclonal antibody to CD20. Blood. 1994;83(2):435-445.

57. Edwards JC, Cambridge G. B-cell targeting in rheumatoid arthritis and other autoimmune diseases. Nat Rev Immunol. 2006;6(5):394-403.

58. McLaughlin P, Grillo-Lopez AJ, Link BK, et al. Rituximab chimeric anti-CD20 monoclonal antibody therapy for relapsed indolent lymphoma: half of patients respond to a four-dose treatment program. J Clin Oncol. 1998;16(8):2825-2833.

59. Henning JS, Firoz BF. Rituxan is not associated with Stevens Johnson Syndrome. Ann Oncol. 2011;22(6):1463-1464.

60. Anhalt GJ, Kim SC, Stanley JR, et al. Paraneoplastic pemphigus: an autoimmune mucocutaneous disease associated with neoplasia. $N E n g l$ J Med. 1990;323(25):1729-1735.

61. Joly P, Richard C, Gilbert D, et al. Sensitivity and specificity of clinical, histologic, and immunologic features in the diagnosis of paraneoplastic pemphigus. J Am Acad Dermatol. 2000;43(4):619-626.

62. Horn TD, Anhalt GJ. Histologic features of paraneoplastic pemphigus. Arch Dermatol. 1992;128(8):1091-1095. 
63. Fallon MJ, Heck JN. Fatal Stevens-Johnson syndrome/toxic epidermal necrolysis induced by allopurinol-rituximab-bendamustine therapy. J Oncol Pharm Pract. 2015;21(5):388-392.

64. Karoulia Z, Gavathiotis E, Poulikakos PI. New perspectives for targeting RAF kinase in human cancer. Nat Rev Cancer. 2017;17(11):676-691.

65. Lacouture ME, Duvic M, Hauschild A, et al. Analysis of dermatologic events in vemurafenib-treated patients with melanoma. Oncologist. 2013;18(3):314-322.

66. Sinha R, Larkin J, Gore M, Fearfield L. Cutaneous toxicities associated with vemurafenib therapy in 107 patients with BRAF V600E mutationpositive metastatic melanoma, including recognition and management of rare presentations. Br J Dermatol. 2015;173(4):1024-1031.

67. de Golian E, Kwong BY, Swetter SM, Pugliese SB. Cutaneous complications of targeted melanoma therapy. Curr Treat Options Oncol. 2016;17(11):57.

68. Arenbergerova M, Mrazova I, Horazdovsky J, Sticova E, Fialova A, Arenberger P. Toxic epidermal necrolysis induced by vemurafenib after nivolumab failure. J Eur Acad Dermatol Venereol. 2017;31(5):e253-e254.

69. Harding JJ, Pulitzer M, Chapman PB. Vemurafenib sensitivity skin reaction after ipilimumab. $N$ Engl J Med. 2012;366(9):866-868.

70. Jeudy G, Dalac-Rat S, Bonniaud B, et al. Successful switch to dabrafenib after vemurafenib-induced toxic epidermal necrolysis. $\mathrm{Br} \mathrm{J}$ Dermatol. 2015;172(5):1454-1455.

71. Wolchok JD, Chiarion-Sileni V, Gonzalez R, et al. Overall survival with combined nivolumab and ipilimumab in advanced melanoma. N Engl J Med. 2017;377(14):1345-1356.

72. Motzer RJ, Escudier B, McDermott DF, et al. Nivolumab versus everolimus in advanced renal-cell carcinoma. $N$ Engl $J$ Med 2015;373(19):1803-1813.

73. Borghaei H, Paz-Ares L, Horn L, et al. Nivolumab versus docetaxel in advanced nonsquamous non-small-cell lung cancer. $N$ Engl J Med. 2015;373(17):1627-1639.

74. Curry JL, Tetzlaff MT, Nagarajan P, et al. Diverse types of dermatologic toxicities from immune checkpoint blockade therapy. J Cutan Pathol. 2017;44(2):158-176.

75. Polder K, Wang C, Duvic M, et al. Toxic epidermal necrolysis associated with denileukin diftitox (DAB389IL-2) administration in a patient with follicular large cell lymphoma. Leuk Lymphoma. 2005;46(12):1807-1811.

76. Wiener JS, Tucker JA Jr, Walther PJ. Interleukin-2-induced dermatotoxicity resembling toxic epidermal necrolysis. South Med J. 1992;85(6):656-659.

77. Huerta AA, Tordera P, Cercos AC, Yuste AL, Lopez-Tendero P, Reynes G. Toxic epidermal necrolysis associated with interleukin-2. Ann Pharmacother. 2002;36(7-8):1171-1174.

78. Nayar N, Briscoe K, Fernandez-Penas P. Toxic epidermal necrolysislike reaction with severe satellite cell necrosis associated with nivolumab in a patient with ipilimumab refractory metastatic melanoma. J Immunother. 2016;39(3):149-152.

79. Goldinger SM, Stieger P, Meier B, et al. Cytotoxic cutaneous adverse drug reactions during anti-PD-1 therapy. Clin Cancer Res. 2016;22(16):4023-4029.

80. Liniker E, Menzies AM, Kong BY, et al. Activity and safety of radiotherapy with anti-PD-1 drug therapy in patients with metastatic melanoma. Oncoimmunology. 2016;5(9):e1214788.

81. Dika E, Ravaioli GM, Fanti PA, et al. Cutaneous adverse effects during ipilimumab treatment for metastatic melanoma: a prospective study. Eur J Dermatol. 2017;27(3):266-270.

82. Hwang SJ, Carlos G, Wakade D, Sharma R, Fernandez-Penas P. Ipilimumab-induced acute generalized exanthematous pustulosis in a patient with metastatic melanoma. Melanoma Res. 2016;26(4):417-420.

83. Voskens CJ, Goldinger SM, Loquai C, et al. The price of tumor control: an analysis of rare side effects of anti-CTLA-4 therapy in metastatic melanoma from the ipilimumab network. PLoS One. 2013;8(1):e53745.
84. Saw S, Lee HY, Ng QS. Pembrolizumab-induced Stevens-Johnson syndrome in non-melanoma patients. Eur J Cancer. 2017;81:237-239.

85. Le Naour S, Peuvrel L, Saint-Jean M, Dreno B, Quereux G. Three new cases of bullous pemphigoid during anti-PD-1 antibody therapy. $J$ Eur Acad Dermatol Venereol. 2018;32(3):e104-e106.

86. Macdonald JB, Macdonald B, Golitz LE, LoRusso P, Sekulic A. Cutaneous adverse effects of targeted therapies - part II: inhibitors of intracellular molecular signaling pathways. J Am Acad Dermatol. 2015;72(2):221-238

87. Saidi W, Lahouel I, Laarif M, Aounallah A. A new case of imatinibinduced drug reaction with eosinophilia and systemic symptoms Indian J Dermatol Venereol Leprol. 2017;83(2):224-226.

88. Hsiao LT, Chung HM, Lin JT, et al. Stevens-Johnson syndrome after treatment with STI571: a case report. Br J Haematol. 2002;117(3) $620-622$.

89. Brouard MC, Prins C, Mach-Pascual S, Saurat JH. Acute generalized exanthematous pustulosis associated with STI571 in a patient with chronic myeloid leukemia. Dermatology. 2001;203(1):57-59.

90. Scott AD, Lee M, Kubba F, Chu A. Acute generalized exanthematous pustulosis (AGEP) secondary to imatinib in a patient with chronic myeloid leukaemia. Clin Exp Dermatol. 2015;40(8):926-927.

91. Shih HC, Hsiao YP, Wu MF, Yang JH. Gefitinib-induced acute generalized exanthematous pustulosis in two patients with advanced non-small-cell lung cancer. Br J Dermatol. 2006;155(5):1101-1102.

92. Sidoroff A, Halevy S, Bavinck JN, Vaillant L, Roujeau JC. Acute generalized exanthematous pustulosis (AGEP): a clinical reaction pattern. J Cutan Pathol. 2001;28(3):113-119.

93. Roe E, Muret MP, Marcuello E, Capdevila J, Pallares C, Alomar A. Description and management of cutaneous side effects during cetuximab or erlotinib treatments: a prospective study of 30 patients. $J \mathrm{Am}$ Acad Dermatol. 2006;55(3):429-437.

94. Brodell LA, Hepper D, Lind A, Gru AA, Anadkat MJ. Histopathology of acneiform eruptions in patients treated with epidermal growth factor receptor inhibitors. J Cutan Pathol. 2013;40(10):865-870.

95. Kardaun SH, Kuiper H, Fidler V, Jonkman MF. The histopathological spectrum of acute generalized exanthematous pustulosis (AGEP) and its differentiation from generalized pustular psoriasis. J Cutan Pathol. 2010;37(12):1220-1229.

96. Halevy S, Kardaun SH, Davidovici B, Wechsler J. The spectrum of histopathological features in acute generalized exanthematous pustulosis: a study of 102 cases. Br J Dermatol. 2010;163(6):1245-1252.

97. Lee YY, Chung WH. Acute generalized exanthematous pustulosis: a retrospective study of 51 cases in Taiwan. Dermatol Sin. 2014;32(3):137-140.

98. Hotz C, Valeyrie-Allanore L, Haddad C, et al. Systemic involvement of acute generalized exanthematous pustulosis: a retrospective study on 58 patients. Br J Dermatol. 2013;169(6):1223-1232.

99. Naranjo CA, Busto U, Sellers EM, et al. A method for estimating the probability of adverse drug reactions. Clin Pharmacol Ther. 1981;30(2):239-245.

100. Sassolas B, Haddad C, Mockenhaupt M, et al. ALDEN, an algorithm for assessment of drug causality in Stevens-Johnson Syndrome and toxic epidermal necrolysis: comparison with case-control analysis. Clin Pharmacol Ther. 2010;88(1):60-68.

101. Guthrie B, Makubate B, Hernandez-Santiago V, Dreischulte T. The rising tide of polypharmacy and drug-drug interactions: population database analysis 1995-2010. BMC Med. 2015;13:74.

102. Heng YK, Lim YL. Cutaneous adverse drug reactions in the elderly. Curr Opin Allergy Clin Immunol. 2015;15(4):300-307.

103. Urosevic-Maiwald M, Harr T, French LE, Dummer R. Stevens-Johnson syndrome and toxic epidermal necrolysis overlap in a patient receiving cetuximab and radiotherapy for head and neck cancer. Int J Dermatol. 2012;51(7):864-867.

104. Imafuku K, Yoshino K, Ishiwata $\mathrm{K}$, et al. Severe rash associated with vemurafenib administration following nivolumab therapy. J Eur Acad Dermatol Venereol. 2016;30(10):e84-e86. 
105. Pichler WJ, Tilch J. The lymphocyte transformation test in the diagnosis of drug hypersensitivity. Allergy. 2004;59(8):809-820.

106. Kano Y, Hirahara K, Mitsuyama Y, Takahashi R, Shiohara T. Utility of the lymphocyte transformation test in the diagnosis of drug sensitivity: dependence on its timing and the type of drug eruption. Allergy. 2007;62(12):1439-1444.

107. Nagao-Dias AT, Teixeira FM, Coelho HL. Diagnosing immune-mediated reactions to drugs. Allergol Immunopathol (Madr). 2009;37(2):98-104.

108. Barbaud A, Collet E, Milpied B, et al. A multicentre study to determine the value and safety of drug patch tests for the three main classes of severe cutaneous adverse drug reactions. Br J Dermatol. 2013;168(3):555-562.

109. Doesch J, Debus D, Meyer C, et al. Afatinib-associated StevensJohnson syndrome in an EGFR-mutated lung cancer patient. Lung Cancer. 2016;95:35-38.

110. Lee SS, Chu PY. Toxic epidermal necrolysis caused by cetuximab plus minocycline in head and neck cancer. Am J Otolaryngol. 2010;31(4):288-290.

111. Pantano F, Silletta M, Iovieno A, et al. Stevens-Johnson syndrome associated with reduced tear production complicating the use of cetuximab and panitunumab [sic]. Int J Colorectal Dis. 2009;24(10):1247-1248.

112. Jackman DM, Cioffredi LA, Jacobs L, et al. A phase I trial of high dose gefitinib for patients with leptomeningeal metastases from non-small cell lung cancer. Oncotarget. 2015;6(6):4527-4536.

113. Huang JJ, Ma SX, Hou X, et al. Toxic epidermal necrolysis related to AP (pemetrexed plus cisplatin) and gefitinib combination therapy in a patient with metastatic non-small cell lung cancer. Chin J Cancer. 2015;34(2):94-98.

114. Yoon J, Oh CW, Kim CY. Stevens-Johnson syndrome induced by vandetanib. Ann Dermatol. 2011;23(Suppl 3):S343-S345.

115. Ladizinski B, Sankey C. A topical matter: toxic epidermal necrolysis. Am J Med. 2014;127(10):931-932.

116. Bois E, Holle LM, Farooq U. Late onset imatinib-induced StevensJohnson syndrome. J Oncol Pharm Pract. 2014;20(6):476-478.

117. Jha P, Himanshu D, Jain N, Singh AK. Imatinib-induced StevensJohnsons syndrome. BMJ Case Rep. 2013;2013.

118. Nakamoto K, Nagahara H, Noda E, et al. [Three cases of giant rectal gastrointestinal stromal tumor]. Gan To Kagaku Ryoho. 2011;38(12): 1984-1986. Japanese.

119. Vidal D, Puig L, Sureda A, Alomar A. Sti571-induced Stevens-Johnson Syndrome. Br J Haematol. 2002;119(1):274-275.

120. Schaich M, Schäkel K, Illmer T, Ehninger G, Bornhauser M. Severe epidermal necrolysis after treatment with imatinib and consecutive allogeneic hematopoietic stem cell transplantation. Ann Hematol. 2003;82(5):303-304.

121. Hsieh HJ, Chan AL, Lin SJ. Stevens-Johnson syndrome induced by combination of imatinib and allopurinol. Chemotherapy. 2009;55(4):197-199.

122. Severino G, Chillotti C, de Lisa R, del Zompo M, Ardau R. Adverse reactions during imatinib and lansoprazole treatment in gastrointestinal stromal tumors. Ann Pharmacother. 2005;39(1):162-164.

123. Goldman J, Duval-Modeste AB, Lambert A, et al. [Imatinib-induced DRESS]. Ann Dermatol Venereol. 2008;135(5):393-396. French.

124. Le Nouail P, Viseux V, Chaby G, Billet A, Denoeux JP, Lok C. [Drug reaction with eosinophilia and systemic symptoms (DRESS) following imatinib therapy]. Ann Dermatol Venereol. 2006;133(8-9 Pt 1):686-688. French.

125. Schwarz M, Kreuzer KA, Baskaynak G, Dorken B, le Coutre P. Imatinib-induced acute generalized exanthematous pustulosis (AGEP) in two patients with chronic myeloid leukemia. Eur J Haematol. 2002;69(4):254-256.
126. Sohn KH, Oh SY, Lim KW, Kim MY, Lee SY, Kang HR. Sorafenib induces delayed-onset cutaneous hypersensitivity: a case series. Allergy Asthma Immunol Res. 2015;7(3):304-307.

127. Alegre-Sanchez A, de Perosanz-Lobo D, Pinilla-Pagnon I, MunozZato E. Sorafenib-induced acute generalized exanthematous pustulosis: an increasing association? Actas Dermosifiliogr. 2017;108(6): 599-601.

128. Liang CP, Yang CS, Shen JL, Chen YJ. Sorafenib-induced acute localized exanthematous pustulosis in a patient with hepatocellular carcinoma. Br J Dermatol. 2011;165(2):443-445.

129. Pretel M, Inarrairaegui M, Lera JM, Aguado L, Idoate MA. Acute generalized exanthematous pustulosis induced by sorafenib. JAMA Dermatol. 2014;150(6):664-666.

130. Fang B, Song Y, Ma J, Zhao RC. Severe epidermal necrolysis after bortezomib treatment for multiple myeloma. Acta Haematol. 2007;118(2):65-67.

131. Castaneda CP, Brandenburg NA, Bwire R, Burton GH, Zeldis JB. Erythema multiforme/Stevens-Johnson syndrome/toxic epidermal necrolysis in lenalidomide-treated patients. J Clin Oncol. 2009;27(1): $156-157$.

132. Hattori N, Adachi D, Nakashima H, Saito B, Nakamaki T, Tomoyasu S. Drug-induced hypersensitivity syndrome after bortezomib treatment for refractory multiple myeloma. Leuk Res. 2009;33(4): 574-577.

133. Lowndes S, Darby A, Mead G, Lister A. Stevens-Johnson syndrome after treatment with rituximab. Ann Oncol. 2002;13(12):1948-1950.

134. Parise L, Kahle J, Schlaak M, Mauch C, Kurschat P. Reply to Rituxan is not associated with Stevens-Johnson syndrome. Ann Oncol. 2012;23(3):807.

135. Foran JM, Gupta RK, Cunningham D, et al. A UK multicentre phase II study of rituximab (chimaeric anti-CD20 monoclonal antibody) in patients with follicular lymphoma, with PCR monitoring of molecular response. Br J Haematol. 2000;109(1):81-88.

136. Newland AM, Li JX, Wasco LE, Aziz MT, Lowe DK. Brentuximab vedotin: a CD30-directed antibody-cytotoxic drug conjugate. Pharmacotherapy. 2013;33(1):93-104.

137. del Principe MI, Sconocchia G, Buccisano F, et al. Extensive toxic epidermal necrolysis following brentuximab vedotin administration. Ann Hematol. 2015;94(2):355-356.

138. Kiliç S, Ozkaya E, Baykal C, Vatansever S. Vemurafenib-induced toxic epidermal necrolysis: is it an emerging side effect of the drug? J Eur Acad Dermatol Venereol. 2017;31(8):e354-e355.

139. Lapresta A, Dotor A, Gonzalez-Herrada C. Toxic epidermal necrolysis induced by vemurafenib. Actas Dermosifiliogr. 2015;106(8): $682-683$.

140. Wantz M, Spanoudi-KITrimi I, Lasek A, Lebas D, Quinchon JF, Modiano P. [Vemurafenib-induced toxic epidermal necrolysis]. Ann Dermatol Venereol. 2014;141(3):215-218. French.

141. Sinha R, Lecamwasam K, Purshouse K, Reed J, Middleton MR, Fearfield $\mathrm{L}$. Toxic epidermal necrolysis in a patient receiving vemurafenib for treatment of metastatic malignant melanoma. $\mathrm{Br} J$ Dermatol. 2014;170(4):997-999.

142. Munch M, Peuvrel L, Brocard A, et al. Early-onset vemurafenibinduced DRESS syndrome. Dermatology. 2016;232(1):126-128.

143. Wenk KS, Pichard DC, Nasabzadeh T, Jang S, Venna SS. Vemurafenibinduced DRESS. JAMA Dermatol. 2013;149(10):1242-1243.

144. Pathria M, Mundi J, Trufant J. A case of Stevens-Johnson syndrome in a patient on ipilimumab. Int J Case Rep Imag. 2016;7(5): $300-302$. 
Cancer Management and Research

\section{Publish your work in this journal}

Cancer Management and Research is an international, peer-reviewed open access journal focusing on cancer research and the optimal use of preventative and integrated treatment interventions to achieve improved outcomes, enhanced survival and quality of life for the cancer patient

The manuscript management system is completely online and includes

Submit your manuscript here: https://www.dovepress.com/cancer-management-and-research-journal

a very quick and fair peer-review system, which is all easy to use. Visit $\mathrm{http}: / / \mathrm{www}$.dovepress.com/testimonials.php to read real quotes from published authors. 